\title{
Erratum to: Proteomics in Energy Crops
}

\author{
Shiva Bakhtiari, Meisam Tabatabaei and Yusuf Chisti
}

\section{Erratum to:}

Chapter 6 in: G.H. Salekdeh (ed.), Agricultural Proteomics Volume 1, DOI 10.1007/978-3-319-43275-5_6

The original version of the book was inadvertently published with old version despite having received the revised manuscript. The erratum chapter and the book have been updated with the revised text.

The updated original online version for this chapter can be found at 10.1007/978-3-319-43275-5_6

\footnotetext{
S. Bakhtiari

Biology Department, Concordia University, 7141 Sherbrooke W., Montreal H4B 1R6, Canada

M. Tabatabaei $(\bowtie)$

Microbial Biotechnology Department, Agricultural Biotechnology Research Institute of Iran (ABRII), Agricultural Research, Education, and Extension Organization (AREEO), Karaj, Iran e-mail: meisam_tabatabaei@abrii.ac.ir; meisam_tab@yahoo.com

M. Tabatabaei

Biofuel Research Team (BRTeam), Karaj, Iran

Y. Chisti

School of Engineering, Massey University,

Private Bag 11 222, Palmerston North, New Zealand 